Magdalena Plutal, , Maria Pokorska-Śpiewak ${ }^{1,2}$, Małgorzata Aniszewska ${ }^{1,2}$, Magdalena Marczyńska ${ }^{1,2}$

\title{
ON A STRAIGHT PATH TO HCV ELIMINATION IN CHILDREN - NEW PROSPECTS FOR HEPATITIS C TREATMENT IN POLAND
}

\section{NA DRODZE DO ELIMINACJI WIRUSOWEGO ZAPALENIA WĄTROBY TYPU C U DZIECI - NOWE MOŻLIWOŚCI LECZENIA WZW C W POLSCE}

\author{
${ }^{1}$ Medical University of Warsaw, Department of Children's Infectious Diseases \\ Warszawski Uniwersytet Medyczny, Klinika Chorób Zakaźnych Dzieci \\ ${ }^{2}$ Warsaw's Hospital for Infectious Diseases, Warsaw, Poland \\ Warszawski Szpital Chorób Zakaźnych
}

\begin{abstract}
Difficulties in achieving elimination targets of the World Health Organization's Global Strategy on viral hepatitis might be overcome through a new micro-elimination approach that allows for a quick, efficient targeting of treatment and prevention services. Particular focus on identification of high-risk and so far marginalized populations, such as children and adolescents, increases chances for HCV elimination on a country, and ultimately on a population level. Therefore, a broad access to safe and highly effective direct-acting antiviral drugs is of upmost importance in the pediatric population.
\end{abstract}

Keywords: hepatitis $C$ in children, treatment, global strategy WHO

\section{STRESZCZENIE}

Wdrożenie nowej strategii, tzw. mikroeliminacji może pozwolić na pokonanie trudności związanych z osiągnięciem celów określonych w Globalnej Strategii Zwalczania Wirusowych Zapaleń Wątroby opracowanej przez Światową Organizację Zdrowia. Mikroeliminacja umożliwia szybkie i efektywne wdrożenie procedur leczniczych i profilaktycznych. Intensyfikacja działań na rzecz identyfikacji grup ryzyka oraz społeczności zmarginalizowanej, w tym dzieci oraz młodzieży, umożliwi zwiększenie szans na eliminację wzw C na poziomie kraju oraz docelowo na poziomie populacji. Zapewnienie szerokiego dostępu do bezpiecznych i wysoce skutecznych leków o bezpośrednim działaniu przeciwwirusowym powinno być jednym z najważniejszych działań podejmowanych na rzecz zwalczania wzw $\mathrm{C}$ w populacji pediatrycznej.

Słowa kluczowe: $w z w C$ u dzieci, leczenie,, strategia $W H O$

Recent advances in the development of antiviral drugs against $\mathrm{HCV}$ have revolutionized the therapy and paved the way for the elimination of chronic hepatitis $\mathrm{C}(\mathrm{CHC})$. Difficulties in achieving time-bound elimination targets of the World Health Organization's Global Strategy on viral hepatitis might be overcome through a new, emerging micro-elimination approach (1-3). Micro-elimination is a strategy that consists in focusing elimination efforts on specific target populations such as high-risk populations or children and adolescents $(1,4,5)$.

So far, pediatric population was not the focus of the elimination strategies due to the lack of approval of direct-acting antivirals (DAA) and funding
Postęp w leczeniu HCV, który dokonał się w ostatnich latach, zrewolucjonizował terapię wirusowego zapalenia wątroby typu C (wzw C), stwarzając możliwość eliminacji przewlekłego wirusowego zapalenia wątroby typu C (pwzw C). Nowa, zyskująca na popularności koncepcja eliminacji wirusowych zapaleń wątroby (wzw), tzw. mikroeliminacja może pozwolić na pokonanie trudności związanych z osiągnięciem celów określonych w Globalnej Strategii opracowanej przez Światową Organizację Zdrowia (1-3). Mikroeliminacja jest strategią zakładającą zintensyfikowanie działań na rzecz eliminacji wzw $\mathrm{C}$ w grupach ryzyka oraz społeczności zmarginalizowanej (w tym wśród dzieci i młodzieży) poprzez

(c) National Institute of Public Health - National Institute of Hygiene / Narodowy Instytut Zdrowia Publicznego - Państwowy Zakład Higieny 
deficiencies (6). In addition, only few national viral hepatitis policies address this population. Fortunately, the standard of care for $\mathrm{CHC}$ is changing rapidly (7-9). Moreover, an early introduction of treatment is considered to be of high cost-effectiveness as it minimizes future morbidity and mortality $(10,11)$. Last year turned out to be a breakthrough for the management of the youngest children living with $\mathrm{CHC}$ in Europe.

Since July 2020, a combination of ledipasvir and sofosbuvir is approved by the European Medicines Agency (EMA) to be used in children who are at least 3 years of age. Since September 2020, a pan-genotypic combination regimen (sofosbuvir/velpatasvir) was authorized (by the EMA) to be used in children who are at least 6 years of age or weigh at least $17 \mathrm{~kg}$.

Although the course of hepatitis $\mathrm{C}$ in pediatric population tends to be milder than in adults, all treatment-naïve and treatment-experienced children with $\mathrm{CHC}$ should be considered for DAA therapy regardless of disease severity in line with the liver societies guidelines (the American Association for the Study of Liver Diseases, the European Association for the Study of the Liver, the Polish Group of Experts for HCV) (Tab. I.) (11-14). Therapy with pegylated interferon and ribavirin is no longer preferred and should be deferred in younger age groups for which DAA regimens are currently unavailable due to high costs $(15,16)$.

Irrespective of safety profile, high efficiency (nearly $100 \%$ ) and long-term socioeconomics benefits, access to oral, interferon-free treatment is restricted not only in Poland but also in other European countries (17). In Poland, DAA regimens are not reimbursed in children and adolescents below the age of 18 by the National Health Fund (NHF). The therapeutic program of the Ministry of Health offers only interferon-based treatment for them. Such treatment is obsolete, of low efficacy (about 30-50\% in chronic infections with HCV genotype 1) and long duration (Annex B.2.: Treatment of chronic hepatitis $\mathrm{C}$ and Annex B.71: Interferon-free treatment for chronic hepatitis C). Moreover, this oldfashioned therapy is associated with numerous side effects (flu-like symptoms, decreased appetite, weight loss, transient growth retardation, thyroid dysfunction, mood and attention disorders, anemia, neutropenia and thrombocytopenia) that often lead to discontinuation of therapy (18-20).

So far, the treatment of HCV-infected children with new antiviral drugs was provided through clinical trials. A remarkable achievement has been made when first real-life DAA therapeutic program for children (aged over 12 years) was launched in Poland. Since July 2019, adolescents with HCV genotype 1 and 4 have finally an opportunity to be cured regardless of disease severity. poprawę świadomości, profilaktyki, diagnostyki oraz dostępu do leczenia (4-6).

Dotychczas populacja pediatryczna była marginalizowana z powodu braku rejestracji leków o bezpośrednim działaniu przeciwwirusowym (DAA) lub braku ich refundacji (7). Niewiele państw uwzględniało dzieci w swych krajowych strategiach na rzecz zwalczania wzw. Dynamiczne zmiany zachodzące w zakresie terapii pwzw $\mathrm{C}$ dają nadzieję na eradykację zakażenia. Wczesne wdrożenie leczenia jest wysoce efektywne kosztowo $\mathrm{z}$ uwagi na redukcję przyszłej chorobowości i śmiertelności (8-10). W minionym roku dokonano w Europie przełomu w zakresie standardu opieki nad najmłodszymi dziećmi z pwzw C.

W lipcu 2020 r. Europejska Agencja Leków zatwierdziła do stosowania u dzieci (w wieku co najmniej 3 lat) preparat złożony ledipasvir/sofosbuvir. We wrześniu 2020 r. zarejestrowano do leczenia preparat pangenotypowy (sofosbuvir/velpatasvir) u dzieci od 6 roku życia lub o masie ciała co najmniej $17 \mathrm{~kg}$.

Mimo iż przebieg wirusowego zapalenia wątroby typu $\mathrm{C}$ u dzieci bywa zwykle łagodniejszy w porównaniu do osób dorosłych, zgodnie z wytycznymi licznych towarzystw naukowych (American Association for the Study of Liver Diseases, European Association for the Study of the Liver, Polska Grupa Ekspertów HCV) włączenie terapii DAA należy rozważyć u wszystkich dzieci z pwzw C (dotychczas nieleczonych, jak i uprzednio leczonych, niezależnie od stopnia zaawansowania choroby) (Tab. I.) (9,11-13). Leczenie skojarzone pegylowanym interferonem i rybawiryną (PEG-INF+RIBA) nie jest zalecane (14).

Pomimo dobrego profilu bezpieczeństwa, wysokiej skuteczności (niemal 100\%) oraz długotrwałych korzyści społeczno-ekonomicznych, dostęp do doustnych, bezinterferonowych terapii dla pacjentów w wieku poniżej 18 lat jest nadal ograniczony w wielu krajach Unii Europejskiej (15). W Polce Narodowy Fundusz Zdrowia (NFZ) refunduje leczenie za pomocą DAA wyłącznie w grupie dorosłych. Program lekowy pacjentów poniżej 18 roku życia obejmuje refundacją jedynie terapię PEG-INF+RIBA. Terapia oparta na interferonie jest przestarzała, charakteryzuje się niską skutecznością (ok. 30-50\% w przewlekłym zakażeniu HCV genotypem 1) oraz długim czasem leczenia (Aneks B.2.: Leczenie przewlekłego wirusowego zapalenia wątroby typu $\mathrm{C}$ oraz Aneks B.71: Leczenie przewlekłego wirusowego zapalenia wątroby typu $\mathrm{C}$ terapią bezinterferonową). Ponadto, jest ona obarczona licznymi działaniami niepożądanymi (objawy grypopodobne, obniżenie apetytu, zmniejszenie masy ciała, przejściowe zaburzenia wzrostu, stymulacja procesów autozapalnych - zaburzenia czynności tarczycy, zaburzenia nastroju, za- 
Non-commercial POLAC Project (Treatment of Polish Adolescents with Chronic Hepatitis C using Direct Acting Antivirals) offering sofosbuvir/ledispavir is conducted by the Department of Children's Infectious Disease at the Medical University of Warsaw.

In March 2020, the Medical Research Agency announced that a non-commercial trial with a newly approved pan-genotypic regimen of sofosbuvir/ velpatasvir for children over 6 years of age from all over Poland will be founded. This study will be conducted in the aforesaid clinical center. First patients are planned to be enrolled in the first quarter of 2021. Prospects for HCV elimination in pediatric population are promising and are currently underway.

Although national surveillance data on hepatitis $\mathrm{C}$ in Poland show a progressive decrease in the number of diagnosed cases, hepatitis $\mathrm{C}$ and its elimination in children should be a public health priority (21-23). In burzenia koncentracji, niedokrwistość, neutropenia i małopłytkowość), które często prowadzą do przerwania terapii (16-18).

Dotychczas leczenie dzieci zakażonych $\mathrm{HCV}$ za pomocą nowych leków przeciwwirusowych było możliwe wyłącznie $\mathrm{w}$ ramach badań klinicznych. W Polsce wdrożenie pierwszego programu terapeutycznego typu real-life opartego na DAA, w ramach którego leczone są dzieci (w wieku 12-18 lat), było przełomowym momentem. Począwszy od lipca 2019 r., młodzieży zakażonej HCV genotypem 1 lub 4 oferuje się nowoczesną terapię, niezależnie od stopnia zaawansowania choroby. Leczenie kombinacją lekową sofosbuvir/ledispavir jest realizowane w ramach niekomercyjnego projektu POLAC (Treatment of Polish Adolescents with Chronic Hepatitis C using Direct Acting Antivirals) prowadzonego przez Klinikę Chorób Zakaźnych Wieku Dziecięcego Warszaw-

Table I. Direct-acting antiviral therapies for children with chronic hepatitis C approved by EMA and available in Poland. Tabela I. Leki o bezpośrednim działaniu przeciwwirusowym stosowane u dzieci z przewlekłym wirusowym zapaleniem wątroby typu C zatwierdzone przez Europejską Agencję Leków i dostępne w Polsce.

\begin{tabular}{|c|c|c|c|c|c|c|}
\hline $\begin{array}{l}\text { Therapeutic } \\
\text { regimens / } \\
\text { Terapia }\end{array}$ & $\begin{array}{l}\text { Available in } \\
\text { Poland*/ } \\
\text { Dostępność } \\
\text { w Polsce* }\end{array}$ & $\begin{array}{c}\text { HCV } \\
\text { genotype / } \\
\text { Genotyp } \\
\text { HCV }\end{array}$ & $\begin{array}{l}\text { Age / } \\
\text { Wiek }\end{array}$ & $\begin{array}{c}\text { Prior treatment / } \\
\text { Historia } \\
\text { wcześniejszego } \\
\text { leczenia }\end{array}$ & $\begin{array}{c}\text { Obecność marskości } \\
\text { wątroby / } \\
\text { Cirrhosis status }\end{array}$ & $\begin{array}{c}\text { Duration of } \\
\text { treatment in } \\
\text { weeks / } \\
\text { Czas leczenia } \\
\text { w tygodniach }\end{array}$ \\
\hline \multirow{3}{*}{$\begin{array}{l}\text { glecaprevir/ } \\
\text { pibrentasvir }\end{array}$} & \multirow{3}{*}{ - } & \multirow{2}{*}{$1-6$} & \multirow{3}{*}{$\begin{array}{l}\geq 12 \text { years } \\
\quad / \text { lat }\end{array}$} & \multirow{2}{*}{$\begin{array}{c}\text { naive or } \\
\text { experienced / } \\
\text { nieleczeni lub } \\
\text { wcześniej leczeni }\end{array}$} & $\begin{array}{l}\text { without cirrhosis / } \\
\text { bez marskości wątroby }\end{array}$ & 8 \\
\hline & & & & & $\begin{array}{c}\text { with cirrhosis / } \\
\text { z marskością wątroby }\end{array}$ & 12 \\
\hline & & 3 & & $\begin{array}{c}\text { experienced / } \\
\text { wcześniej leczeni }\end{array}$ & $\begin{array}{l}\text { without or with cirrhosis / } \\
\text { bez lub z marskością } \\
\text { wątroby }\end{array}$ & 16 \\
\hline $\begin{array}{l}\text { sofosbuvir/ } \\
\text { velpatasvir }\end{array}$ & + & $1-6$ & $\begin{array}{l}\geq 6 \text { years } \\
/ \text { lat }\end{array}$ & $\begin{array}{c}\text { naive or } \\
\text { experienced / } \\
\text { nieleczeni lub } \\
\text { wcześniej leczeni }\end{array}$ & $\begin{array}{c}\text { without or with cirrhosis / } \\
\text { bez lub z marskością } \\
\text { wątroby }\end{array}$ & 12 \\
\hline \multirow{4}{*}{$\begin{array}{l}\text { ledipasvir/ } \\
\text { sofosbuvir }\end{array}$} & \multirow{4}{*}{+} & \multirow{3}{*}{1} & \multirow{4}{*}{$\begin{array}{l}\geq 3 \text { years } \\
\text { / lat }\end{array}$} & $\begin{array}{l}\text { naive / } \\
\text { nieleczeni }\end{array}$ & $\begin{array}{c}\text { without or with cirrhosis / } \\
\text { bez lub z marskością } \\
\text { wątroby }\end{array}$ & \multirow[t]{2}{*}{12} \\
\hline & & & & $\begin{array}{c}\text { experienced / } \\
\text { wcześniej leczeni }\end{array}$ & $\begin{array}{c}\text { without cirrhosis / } \\
\text { bez marskości wątroby }\end{array}$ & \\
\hline & & & & $\begin{array}{c}\text { experienced / } \\
\text { wcześniej leczeni }\end{array}$ & $\begin{array}{c}\text { with cirrhosis / } \\
\text { z marskością wątroby }\end{array}$ & 24 \\
\hline & & $4,5,6$ & & $\begin{array}{c}\text { naive or } \\
\text { experienced / } \\
\text { nieleczeni lub } \\
\text { wcześniej leczeni }\end{array}$ & $\begin{array}{c}\text { without or with cirrhosis / } \\
\text { bez lub z marskością } \\
\text { wątroby }\end{array}$ & 12 \\
\hline \multirow[b]{2}{*}{$\begin{array}{l}\text { sofosbuvir }+ \\
\text { ribavirin }\end{array}$} & \multirow[b]{2}{*}{ - } & 2 & \multirow[b]{2}{*}{$\begin{array}{l}\geq 3 \text { years } \\
/ \text { lat }\end{array}$} & \multirow{2}{*}{$\begin{array}{c}\text { naive or } \\
\text { experienced / } \\
\text { nieleczeni lub } \\
\text { wcześniej leczeni }\end{array}$} & \multirow{2}{*}{$\begin{array}{l}\text { without or with cirrhosis / } \\
\text { bez lub z marskością } \\
\text { wątroby }\end{array}$} & 12 \\
\hline & & 3 & & & & 24 \\
\hline
\end{tabular}

*lack of reimbursement, offered in non-commercial trials

Note. Data from the reports of the European Medicine Agency retrieved from: https://www.ema.europa.eu/en

*brak refundacji, leczenie oferowane w ramach niekomercyjnych badań klinicznych 
order to reach the WHO's goal of HCV elimination by 2030 , all aspects including awareness, prevention, diagnosis and treatment should be addressed. Pediatricians and primary care physicians play a key role in the implementation and functioning of integrated standard HCV care pathway which consists of planning and provision of routine screening and referral of newly diagnosed children and adolescents to pediatric hepatologists/pediatric infectious diseases specialists who would offer high-quality treatment, care and support (24-26). Recently approved regimens, some of pan-genotypic activity, seem to be a game changer in HCV elimination in pediatric population as they serve as a prevention of future horizontal and vertical transmission. Moreover, they prevent further discrimination and stigmatization of infected people that is driven by public misunderstanding of hepatitis $\mathrm{C}$ transmission.

\section{REFERENCES}

1. Lazarus J V., Wiktor S, Colombo M, et al. Microelimination - A path to global elimination of hepatitis C. J Hepatol 2017;67:665-6.

2. Lazarus J V., Safreed-Harmon K, Thursz MR, et al. The Micro-Elimination Approach to Eliminating Hepatitis C: Strategic and Operational Considerations. Semin. Liver Dis. 2018;38:181-92.

3. World Health Organization (WHO). Global health sector strategy on viral hepatitis 2016-2021. Toward ending viral hepatitis. Geneva: 2016. http://www. who.int/hepatitis/strategy2016-2021/ghss-hep/en/

4. van Dijk M, Drenth JPH, Arends JE, et al. Loss to follow-up in the hepatitis $\mathrm{C}$ care cascade: A substantial problem but opportunity for microelimination. J Viral Hepat 2020;:1-14.

5. The Lancet HIV. The Lancet Hiv. Microelimination could be a big deal for HCV and HIV services. Lancet HIV 2018;5:e605.

6. El-Sayed MH, Indolfi G. Hepatitis C Virus Treatment in Children: A Challenge for Hepatitis C Virus Elimination. Semin Liver Dis Published Online First: 2020.

7. Jonas $\mathrm{M}$, Lon $\mathrm{H}$, Rhee $\mathrm{S}$, et al. Pharmacokinetics of Glecaprevir/Pibrentasvir in children with chronic HCV infection: interim analysis of part 2 of the Dora study. Poster presentation at the Annual Meeting of the American Association for the Study of Liver Diseases (AASLD), November 8-12, 2019.

8. Jonas MM, Romero R, Sokal E, et al. Safety and efficacy of sofosbuvir/ velpatasvir (SOF/VEL) in pediatric patients 6 to $<18$ years old with chronic hepatitis c (CHC) infection. Gut 2020;69(Suppl 2):A74. skiego Uniwersytetu Medycznego, we współpracy z Wojewódzkim Szpitalem Zakaźnym w Warszawie.

W marcu 2020 r. Agencja Badań Medycznych przyznała grant na realizację niekomercyjnego badania klinicznego z zastosowaniem nowo zatwierdzonego leku pangenotypowego (sofosbuvir/velpatasvir) u dzieci w wieku 6-18 lat pochodzących z całej Polski. Projekt jest realizowany przez w/w Klinikę. Pierwsi pacjenci zostaną włączeni do badania w pierwszym kwartale 2021 r. Perspektywa eliminacji HCV w populacji pediatrycznej jest obiecująca i w rzeczywistości jest już realizowana.

Pomimo, iż dane $\mathrm{z}$ nadzoru epidemiologicznego nad wirusowym zapaleniem wątroby typu $C$ w Polsce sugerują stopniowy spadek liczby rozpoznanych przypadków, wirusowe zapalenie wątroby typu $\mathrm{C}$ oraz eliminacja wzw $\mathrm{C}$ u dzieci powinny być postrzegane jako priorytet zdrowia publicznego (19-21). Należy wzmóc działania na rzecz poprawy świadomości, profilaktyki, diagnostyki oraz leczenia wzw C, aby cele Globalnej Strategii eliminacji HCV miały szansę zostać osiągnięte do 2030 r. Pediatrzy oraz lekarze podstawowej opieki zdrowotnej powinni odgrywać kluczową rolę $\mathrm{w}$ procesie wdrażania i funkcjonowania zintegrowanego standardu opieki nad pacjentami zakażonymi HCV, obejmującego identyfikację zakażonych oraz skierowanie nowo rozpoznanych pacjentów do specjalistów hepatologii dziecięcej/ chorób zakaźnych, którzy zapewnią wysokiej jakości leczenie, opiekę oraz wsparcie (22-24). Ostatnio zarejestrowane schematy terapeutyczne, w tym oparte na lekach pangenotypowych, mogą okazać się przełomem $\mathrm{w}$ zakresie eliminacji wzw C u dzieci i młodzieży. W skali populacji mogą zapobiec przyszłym zakażeniom horyzontalnym i wertykalnym. Zapewnienie szerokiego dostępu do bezpiecznych i wysoce skutecznych leków o bezpośrednim działaniu przeciwwirusowym pozwoliłoby ponadto ograniczyć dyskryminację i stygmatyzację dzieci zakażonych HCV.

9. Wen J, Whitworth S, Leung D, et al. Long term follow-up of safety and efficacy of sofosbuvir-based HCV DAAs in pediatric patients. Hepatology 2020;72:565A-565A.

10. Nguyen J, Barritt A, Jhaveri RR. Cost effectiveness of early treatment with direct-acting antiviral therapy in adolescent patients with hepatitis C infection. J Pediatr 2019;107:90-96.

11. Indolfi G, Easterbrook P,Dusheiko G, et al. Hepatitis $\mathrm{C}$ virus infection in children and adolescents. Lancet Gastroenterol Hepatol 2019;4:477-87.

12. Ghany MG, Marks KM, Morgan TR, et al. Hepatitis C Guidance 2019 Update: AASLD- 
IDSA Recommendations for Testing, Managing, and Treating Hepatitis C Virus Infection. 2020.

13. Pawlotsky JM, Negro F, Aghemo A, et al. EASL recommendations on treatment of hepatitis C: Final update of the series. J Hepatol 2020;73:1170-218.

14. Halota W, Flisiak R, Juszczyk J, et al. Recommendations of the Polish group of experts for HCV for the treatment of hepatitis C in 2020. Clin Exp Hepatol 2020;6:163-9.

15. Pawlotsky J-M, Negro F, Aghemo A, et al. EASL Recommendations on Treatment of Hepatitis C 2018. J Hepatol 2018;69:461-511.

16. Pawlowska M, Sobolewska-Pilarczyk M, Domagalski K. Hepatitis C virus infection in children in the era of direct-acting antiviral. World J Gastroenterol 2018;24:2555-66.

17. Leblebicioglu H, Arends JE, Ozaras R, et al. Availability of hepatitis C diagnostics and therapeutics in European and Eurasia countries. Antiviral Res 2018;150:9-14.

18. Garazzino S, Calitri C, Versace A, et al. Natural history of vertically acquired HCV infection and associated autoimmune phenomena. 2014;:102531.

19. Wiśniewska-Ligier M, Pawłowska M, Pilarczyk $M$, et al. Efficacy of pegylated interferon $\alpha-2 b$ and ribavirin in chronic hepatitis c virus (genotypes 1 and 4) infection. J Pediatr Gastroenterol Nutr 2013;57:694-9.

20. Pawlowska M, Pilarczyk M, Foksinska A, et al. Hematological adverse events and sustained viral response in children undergoing therapy for chronic hepatitis C infection. Hepat Mon 2011;11:968-74.
21. Zakrzewska K, Stępień M, Rosińska M. Hepatitis C in Poland in 2018. Przegl Epidemiol 2020;74(2):209-22.

22. Zakrzewska K, Stępień M, Rosińska M. Hepatitis C in Poland in 2017 Przegl Epidemiol 2019;73(2);167-78.

23. Zakrzewska K, Stępień M, Szumlik K, et al. Hepatitis C in Poland in 2016. Przegl Epidemiol 2018;72(2):157-67.

24. Hatzakis A. Hepatitis C Elimination in Europe. European Policy Guidelines. 2017. http://www. hcvbrusselssummit.eu/

25. Thomas DL. State of the Hepatitis C Virus Care Cascade. Clin Liver Dis 2020;16:8-11.

26. Hollande C, Parlati L, Pol S. Micro-elimination of hepatitis C virus. Liver Int 2020;40:67-71.

Received: 1.02.2021

Accepted for publication: 5.03.2021

Otrzymano: 1.02.2021 r.

Zaakceptowano do publikacji: 5.03.2021 $\mathrm{r}$.

\section{Address for correspondence:}

Adres do korespondencji:

Magdalena Pluta MD,

Department of Children's Infectious Diseases, Medical

University of Warsaw, Poland;

Wolska 37 Street;

01-201 Warsaw, Poland

Fax: +48223355253

Phone: +48223355250

e-mail: magdalena.pluta@lekarz.eu 